\title{
SINGLE VERSUS MULTIPLE TRIAL VECTORS IN CLASSICAL DIFFERENTIAL EVOLUTION FOR OPTIMIZING THE QUANTIZATION TABLE IN JPEG BASELINE ALGORITHM
}

\author{
B. Vinoth Kumar ${ }^{1}$ and G.R. Karpagam ${ }^{2}$ \\ Department of Computer Science and Engineering, PSG College of Technology, India
}

\begin{abstract}
Quantization Table is responsible for compression / quality trade-off in baseline Joint Photographic Experts Group (JPEG) algorithm and therefore it is viewed as an optimization problem. In the literature, it has been found that Classical Differential Evolution (CDE) is a promising algorithm to generate the optimal quantization table. However, the searching capability of CDE could be limited due to generation of single trial vector in an iteration which in turn reduces the convergence speed. This paper studies the performance of CDE by employing multiple trial vectors in a single iteration. An extensive performance analysis has been made between $C D E$ and $C D E$ with multiple trial vectors in terms of Optimization process, accuracy, convergence speed and reliability. The analysis report reveals that $C D E$ with multiple trial vectors improves the convergence speed of CDE and the same is confirmed using a statistical hypothesis test (t-test).
\end{abstract}

Keywords:

Meta-Heuristic Search, Differential Evolution, Trial Vectors, Image Compression, JPEG, Quantization Table, Optimization, Statistical Hypothesis Test and t-Test

\section{INTRODUCTION}

Joint Photographic Experts Group (JPEG) is a famous still image compression standard and it is dominating the other image file formats. According to w3tech survey [1], around $73.9 \%$ of images on the internet are in JPEG format. In a JPEG baseline algorithm [2], there are four major steps, namely (i) Dividing an image into $8 \times 8$ blocks, (ii) Applying Discrete Cosine Transform for each block, (iii) Performing quantization for each block and (iv) Applying entropy encoding for each block. Among these steps, quantization plays a significant role in image quality / compression trade-off. Quantization is performed by $8 \times 8$ quantization table which is recommended by the Independent JPEG Group (IJG). Also, this group allows the users to customize the quantization table for their applications.

Many researchers tried to optimize the quantization table using meta-heuristic approaches [3]-[4] such as Simulated Annealing [5], Genetic Algorithm [6]-[12], Chaos Evolutionary Programming [13], Particle Swarm Optimization [14], Firefly algorithm [15], Differential Evolution [16]-[17] and Quantum Genetic Algorithm [18]. Kumar et al. [10] has been proved that Classical Differential Evolution (CDE) is a promising technique to optimize the quantization table for the JPEG baseline algorithm.

Storn and Price [19] introduced a population based optimization algorithm called Differential Evolution (DE). Initialization, Mutation, Crossover and Selection are the important operators in DE algorithm. There are two crossover strategies, namely binomial and exponential, used in the DE algorithm. There are many DE variants such as DE/Rand/1, DE/Rand/2, DE/Best/1, DE/Best/2, [19]-[20] available in the literature by varying the above said operators. Among these variants, "DE/Rand/1/bin" is identified as a Classical Differential Evolution in which the exploration capability is very strong and it is suitable for multimodal problems [21]-[22]. In CDE, only one trial vector will be generated which could limit the convergence speed. Some researchers tried to improve the convergence speed by employing multiple trial vectors in different DE variants [23][24]. However, the employing of multiple trial vectors would increase the computation time for a high dimensional combinatorial problem such as quantization table optimization. Therefore, the number of trial vectors plays an important role for this kind of problem. Although employing of multiple trail vectors in the DE algorithm are available in the literature, it has been never used for this application.

This paper studies whether the performance of CDE can be improved by employing multiple trail vectors in a single iteration. The performance of CDE with multiple trial vectors is analyzed by Average Best Unfitness value, Average Best of Generations, Optimization Accuracy, Probability of Convergence, Average number of function Evaluations and Successful Performance. The analysis reports prove that $\mathrm{CDE}$ with multiple trial vectors performs better than CDE and the same is confirmed by using a statistical hypothesis test.

The rest of this paper is organized as follows. A brief review of the $\mathrm{CDE}$ algorithm is given in section 2. Section 3 illustrates the $\mathrm{CDE}$ with multiple trial vectors. The various performance measures are explained in section 4 . The experiments and results are discussed in section 5. Final thoughts are concluded in section 6 .

\section{CLASSICAL DIFFERENTIAL EVOLUTION (CDE)}

From the current population $G$, the mutant vector $v_{i, G}$ is calculated as shown in Eq.(1) by using the randomly selected three chromosomes $x_{r 1, G}, x_{r 2, G}$ and $x_{r 3, G}$. Here the scaling factor $F$ is chosen between 0 and 1 to control the evolution. A binomial uniform crossover based on crossover probability $C_{r}$ is performed between mutant vector $v_{i, G}$ and target vector $x_{i, G}$ to form trial vector $u_{i, G}$. It is shown in Eq.(2). A better vector is selected for next generation $G+1$ as shown in Eq.(3). The algorithm 1 shows the pseudo code of CDE, which is adopted from Kumar et al. [16].

$$
\begin{gathered}
v_{i, G}=x_{r 1, G}+F\left(x_{r 2, G}-x_{r 3, G}\right) \\
u_{i, G}=u_{j, i, G}=\left\{\begin{array}{lc}
v_{j, i, G} & \text { if }\left(\operatorname{rand}_{j}(0,1) \leq C_{r} \text { or } j=j_{\text {rand }}\right) \\
x_{j, i, G} & \text { otherwise }
\end{array}\right.
\end{gathered}
$$




$$
x_{i, G+1}=\left\{\begin{array}{lc}
x_{i, G} & \text { if }\left(\operatorname{fitness}\left(x_{i, G}\right) \leq \operatorname{fitness}\left(u_{i, G}\right)\right) \\
u_{i, G} & \text { otherwise }
\end{array}\right.
$$

\section{Algorithm 1: Classical Differential Evolution-Pseudo Code}

Initialize population of vectors randomly;

Evaluate the vectors;

While Maximum Generation not reached do

For all vectors do

Select the target vector;

Choose 3 vectors in the population randomly;

Compute the mutant vector;

Perform crossover between the target and mutant vectors to form trial vector;

Evaluate the trial vector;

Replace target vector by trial vector if unfitness value of trial vector is smaller than target vector;

End for

End while

Return best vector;

\section{CDE WITH MULTIPLE TRIAL VECTORS}

The mutant vector in CDE is computed by taking the difference between two random vectors. But all difference vectors have a negative counterpart and an equal chance of being chosen [25].

$$
\begin{aligned}
& v_{i, G}=x_{r 1, G}+F\left(x_{r 2, G}-x_{r 3, G}\right) \\
& v_{\hat{i}, G}=x_{r 1, G}+F\left(x_{r 3, G}-x_{r 2, G}\right) \\
& u_{i, G}=u_{j, i, G}=\left\{\begin{array}{cc}
v_{j, i, G} & \text { if }\left(\operatorname{rand}_{j}(0,1) \leq C_{r} \text { or } j=j_{\text {rand }}\right) \\
x_{j, i, G} & \text { otherwise }
\end{array}\right. \\
& u_{\hat{i}, G}=u_{j, \hat{i}, G}=\left\{\begin{array}{lc}
v_{j, \hat{i}, G} & \text { if }\left(\operatorname{rand}_{j}(0,1) \leq C_{r} \text { or } j=j_{\text {rand }}\right) \\
x_{j, i, G} & \text { otherwise }
\end{array}\right.
\end{aligned}
$$

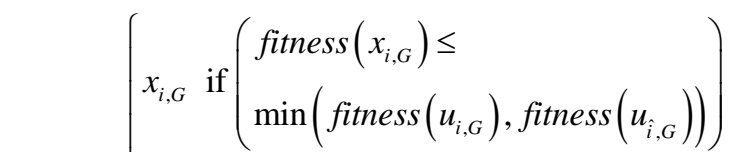

$$
\begin{aligned}
& x_{i, G+1}=\left\{\begin{array}{l}
u_{i, G} \text { if }\left(\begin{array}{l}
\operatorname{fitness}\left(u_{i, G}\right) \leq \\
\min \left(\operatorname{fitness}\left(x_{i, G}\right), \operatorname{fitness}\left(u_{\hat{i}, G}\right)\right)
\end{array}\right) \\
u_{\hat{i}, G} \quad \text { otherwise }
\end{array}\right.
\end{aligned}
$$

Here, the difference between two random vectors and its negative counterpart is taken; accordingly two separate mutant vectors are obtained. The $\mathrm{CDE}$ with multiple trial vectors is represented as DE/Rand $/ * /$ bin. The computation of mutant vector in the DE/Rand/1*/bin is shown in Eq.(4). In each generation two separate trial vectors are computed which is shown in Eq.(5) and Eq.(6). Both the trial vectors are evaluated by fitness function and the best among them is considered to compare with the target vector, shown in Eq.(7).

\section{PERFORMANCE MEASURES}

In order to compare the performance of $\mathrm{CDE}$ and $\mathrm{CDE}$ with

\begin{tabular}{|c|c|c|}
\hline Measure & Description & $\begin{array}{c}\text { Evaluation } \\
\text { Criteria }\end{array}$ \\
\hline $\begin{array}{c}\text { Average Best } \\
\text { Unfitness } \\
\text { Value } f_{a}(k)\end{array}$ & $\begin{array}{l}\text { Calculates the best unfitness value after } \\
\text { particular computation time } k \text {, averaged } \\
\text { over the total number of independent } \\
\text { runs } n \text {. } \\
f_{a}(k)=\frac{\sum_{\text {runs }=1}^{n} \text { Best Unfitness value }(k)}{n}\end{array}$ & $\begin{array}{l}\text { Entire } \\
\text { optimization } \\
\text { process }\end{array}$ \\
\hline $\begin{array}{l}\text { Average Best } \\
\text { of generation } \\
\qquad B O G\end{array}$ & $\begin{array}{l}\text { Calculates the best-of-generation } \\
\text { unfitness over all particular computation } \\
\text { time } k \text {, and over the total number of runs } \\
n . \\
\qquad \overline{B O G}=\frac{1}{n} \frac{1}{k} \sum_{r=1}^{n} \sum_{g=1}^{k} f\left(B O G_{r g}\right) \\
\text { where } f\left(B O G_{r g}\right) \text { expresses the unfitness } \\
\text { value of the best solution at generation } g \\
\text { of run } r \text { (among } n \text { independent runs). }\end{array}$ & $\begin{array}{l}\text { Entire } \\
\text { optimization } \\
\text { process }\end{array}$ \\
\hline $\begin{array}{c}\text { Optimization } \\
\text { Accuracy } A c c_{k}\end{array}$ & $\begin{array}{l}\text { Determines the location of the best found } \\
\text { solution between the lower (worst known } \\
\text { solution) and upper bound (best known } \\
\text { solution). It may vary from } 0 \text { (worst) to } 1 \\
\text { (best). } \\
\qquad A c c_{k}=\frac{f_{a}(k)-\operatorname{Min}_{s}}{M a x_{s}-\operatorname{Min}_{s}} \\
\text { where, } f_{a}(k)=\text { Average best Unfitness } \\
\text { value at a particular generation } k \\
\text { Min }_{s}=\text { Worst known solution, Max } \\
\text { Best known solution }\end{array}$ & Accuracy \\
\hline $\begin{array}{c}\text { Probability of } \\
\text { Convergence, } \\
P\end{array}$ & $\begin{array}{l}\text { Calculates the number of successful } \\
\text { trials }(s) \text { in the total number of } \\
\text { independent runs (n) } \\
\qquad P=\frac{s}{n} \\
\text { It may vary from } 0 \text { (worst) to } 1 \text { (best). }\end{array}$ & Reliability \\
\hline $\begin{array}{c}\text { Average } \\
\text { number of } \\
\text { Function } \\
\text { Evaluations, } \\
\text { AFES }\end{array}$ & $\begin{array}{l}\text { Calculates the average number of } \\
\text { evaluations required to reach the vicinity } \\
\text { of the best known value in each } \\
\text { successful trial. A lower value is } \\
\text { preferred. } \\
\qquad A F E S=\frac{1}{s} \sum_{i=1}^{s} E V A L_{i} \\
\text { where, } E V A L_{i}=\text { number of function } \\
\text { evaluation in the successful run } i\end{array}$ & $\begin{array}{c}\text { Convergence } \\
\text { speed }\end{array}$ \\
\hline $\begin{array}{c}\text { Successful } \\
\text { Performance, } \\
\text { SP }\end{array}$ & $\begin{array}{l}\text { Calculates the ratio of average number of } \\
\text { function evaluations to the probability of } \\
\text { convergence }\end{array}$ & $\begin{array}{c}\text { Convergence } \\
\text { speed }\end{array}$ \\
\hline
\end{tabular}
multiple trial vectors (CDE-MTV), the measures given in Table.1 are taken from the paper [16] [17] to validate the efficiency of both algorithms.

Table.1. Performance Measures to Evaluate the algorithms 


\begin{tabular}{|c|c|c|}
\hline SP $=\frac{A F E S}{P}$ & and \\
& Reliability \\
& A lower value is preferred. & \\
\hline
\end{tabular}

\section{EXPERIMENTAL DISCUSSIONS}

RESULTS

AND

The focus of this paper is to optimize the quantization table using CDE by employing multiple trial vectors. Here every Quantization table which is an $8 \times 8$ vector which has 64 elements. An unfitness function used in this study to evaluate the quantization table is shown in Eq.(8).

$$
\xi=a\left(8 / B_{r}-\lambda\right)^{2}+\varepsilon
$$

where, $a=10, B_{r}=$ Bit rate, $\lambda=$ desired compression ratio = $8 /$ (target bits per pixel), $\varepsilon=$ Mean squared error.

For a basic understanding of CDE with multiple trial vectors, a simple example is shown in Table.2. In this example the initial population is 4 , scaling factor $F$ is a 0.3 and crossover probability is 0.8 . The unfitness values of the initial population are $\{164.34$, 476.45, 157.49, 193.48\}.

For each generation the CDE with multiple trial vectors generates two trial vectors. The unfitness values of these trial vectors are compared with target vector and the one with least unfitness value is selected for next population. The unfitness values after two generations are $\{115.30,146.98,157.49$, 136.79\}.

The Algorithms are implemented in Matlab R2008b and Dell workstation of Intel® Xenon ${ }^{\circledR}$ CPU E3-1240 V3 @ $3.40 \mathrm{GHz}$ processor with $16 \mathrm{~GB}$ of RAM. CDE and CDE with multiple trial vectors have been run for the standard benchmark images shown in Fig. 1. All the images are grey scale with size of $256 \times 256$. The parameter settings for both the algorithms are shown in Table.3.

The programs executed 20 times for each image against each of the target bits/pixel: 0.75 and 1.0 and 1.5. The quality of quantization Table.is evaluated by employing two performance measures; Mean Squared Error (MSE) and Peak Signal to Noise Ratio (PSNR). The mean result among 20 runs for CDE-MTV based quantization table, CDE based quantization table and default JPEG quantization tables is presented in Table.4.

From the Table.4, it is clearly shown that CDE-MTV based quantization table yields better results than other two with less MSE and high PSNR. CDE-MTV quantization tables reduces the MSE on an average by $15.6 \%$ and $23.14 \%$ over the CDE based quantization tables and default JPEG quantization tables respectively.

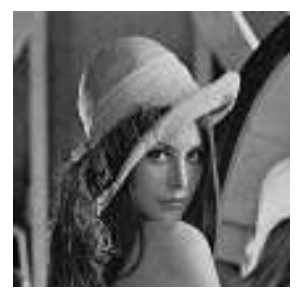

(a)

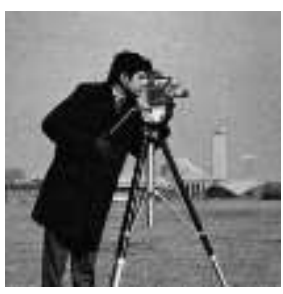

(b)

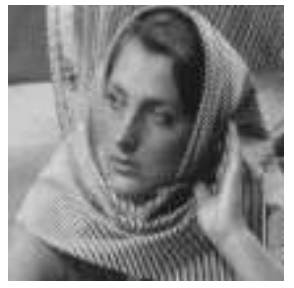

(c)

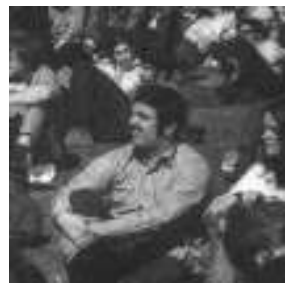

(e)

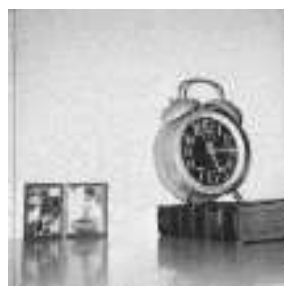

$(\mathrm{g})$

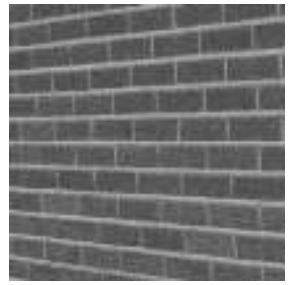

(i)

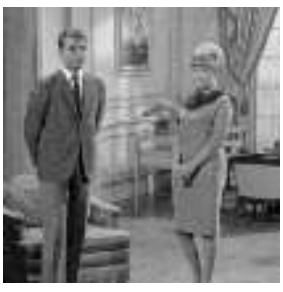

(d)

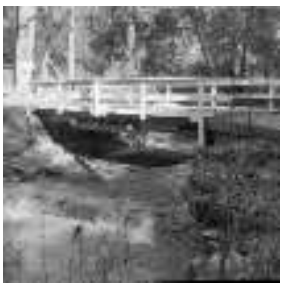

(f)

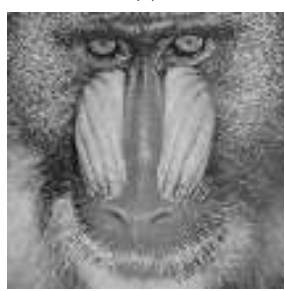

(h)

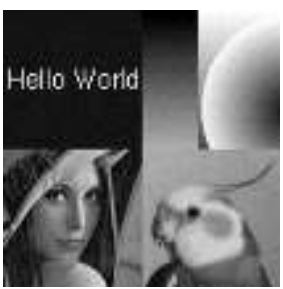

(j)
Fig.1. Standard benchmark images (a) lena (b) camera man (c) barbara (d) couple (e) crowd (f) bridge (g) clock (h) baboon (i) pattern (j) montage

To analyze the performance of CDE and CDE with multiple trial vectors in detail, the measures given in Table. 1 have been taken into consideration. These measures are calculated for ten different images shown in Fig.1 with three different target bits/pixel $0.75,1.0$ and 1.5 in 20 independent runs. The summary results of the performance measures are reported in Table.5Table.10, and measure by measure analyzation is given in the subsequent paragraphs.

Table.5 shows the average best unfitness value at various computation times for different target bits/pixel. From the Table.5, it is clear that CDE with multiple trial vectors has better unfitness value over CDE after each particular computation time. In addition, CDE with multiple trial vectors achieves the better $f_{a}(k)$ than CDE in 2000 seconds where the same is achieved by CDE within 4000 seconds.

Average best-of-generation for the periods 1 to 1000 seconds, 1001 to 2000 seconds, 2001 to 3000 seconds and 3001 to 4000 seconds are summarized in Table. 6 for different target bits/pixel. From the Table.6, it is clearly seen that the $\overline{B O G}$ of CDE with multiple trial vectors in each period is lesser than CDE, which 
confirms that $\mathrm{CDE}$ with multiple trial vector is better than $\mathrm{CDE}$ for the entire optimization process.

Table.2. An example for CDE with Multiple Trial Vectors progress

\begin{tabular}{|c|c|c|c|c|}
\hline \multicolumn{5}{|c|}{ First Generation Second Generation } \\
\hline $\begin{array}{c}\text { Initial } \\
\text { Population }\end{array}$ & $\begin{array}{c}\text { Trial } \\
\text { Vectors }\end{array}$ & $\begin{array}{c}\text { Selection/ } \\
\text { Population for } \\
\text { next generation }\end{array}$ & $\begin{array}{c}\text { Trial } \\
\text { Vectors }\end{array}$ & $\begin{array}{c}\text { Selection/ } \\
\text { Population for } \\
\text { next generation }\end{array}$ \\
\hline 164.34 & \begin{tabular}{|l|}
226.86 \\
153.22
\end{tabular} & 153.22 & $\begin{array}{l}115.30 \\
167.90\end{array}$ & 115.30 \\
\hline 476.45 & $\begin{array}{l}363.43 \\
195.02\end{array}$ & 195.02 & $\begin{array}{l}272.23 \\
146.98\end{array}$ & 146.98 \\
\hline 157.49 & \begin{tabular}{|l|}
169.56 \\
259.08
\end{tabular} & 157.49 & $\begin{array}{l}233.52 \\
237.65\end{array}$ & 157.49 \\
\hline 193.48 & $\begin{array}{l}144.33 \\
203.89\end{array}$ & 144.33 & $\begin{array}{l}152.92 \\
136.79\end{array}$ & 136.79 \\
\hline
\end{tabular}

Table.3. Parameter settings for CDE and CDE with multiple trial vectors (CDE-MTV)

\begin{tabular}{|c|c|c|}
\hline Parameter & CDE & CDE-MTV \\
\hline Population Size & 32 & 32 \\
\hline Scaling Factor & 0.3 & 0.3 \\
\hline Crossover Probability & 0.8 & 0.8 \\
\hline Computation time & $4000 \mathrm{sec}$ & $4000 \mathrm{sec}$ \\
\hline
\end{tabular}

Table.7 summarizes the optimization accuracy value after 1000, 2000, 3000 and 4000 seconds for different target bits/pixel. From the Table.7, it has been noted that the $A c c_{k}$ of CDE with multiple trial vectors in 2000 seconds is same as CDE in 4000 seconds, which shows CDE with multiple trial vectors is very close to an optimal solution in a lesser time.

Table.4. Comparison of image quality measures for CDE and CDE with Multiple Trial vectors (CDE-MTV)

\begin{tabular}{|c|c|c|c|c|c|c|c|}
\hline \multicolumn{2}{|c|}{ Target Bits/Pixel } & \multicolumn{2}{|c|}{0.75} & \multicolumn{2}{|c|}{1} & \multicolumn{2}{|c|}{1.5} \\
\hline Image & $\begin{array}{c}\text { Quantization } \\
\text { Table } \\
\end{array}$ & MSE & $\begin{array}{l}\text { PSNR } \\
\text { in dB }\end{array}$ & MSE & $\begin{array}{l}\text { PSNR } \\
\text { in dB }\end{array}$ & MSE & \begin{tabular}{|l} 
PSNR \\
in dB
\end{tabular} \\
\hline \multirow{3}{*}{ Lena } & JPEG & 51.96 & 31.01 & 34.29 & 32.81 & 19.26 & 35.31 \\
\hline & CDE & 46.83 & 31.46 & 35.61 & 32.65 & 19.87 & 35.18 \\
\hline & CDE-MTV & 43.58 & 31.77 & 27.39 & 33.79 & 14.69 & 36.5 \\
\hline \multirow{3}{*}{$\begin{array}{c}\text { Camera } \\
\text { Man }\end{array}$} & JPEG & 66.24 & 29.95 & 44.25 & 31.71 & 22.29 & 34.68 \\
\hline & CDE & 54.73 & 30.78 & 35.34 & 32.68 & 20.06 & 35.15 \\
\hline & CDE-MTV & 51.81 & 31.02 & 30.41 & 33.34 & 12.98 & 37.03 \\
\hline \multirow{3}{*}{ Barbara } & JPEG & 61.71 & 30.26 & 41.93 & 31.94 & 16.92 & 35.88 \\
\hline & CDE & 51.05 & 31.09 & 33.38 & 32.39 & 16.39 & 36.02 \\
\hline & CDE-MTV & 43.33 & 31.79 & 29.56 & 33.46 & 11.67 & 37.49 \\
\hline \multirow{3}{*}{ Clock } & JPEG & 24.28 & 34.31 & 14.64 & 36.51 & 7.21 & 39.58 \\
\hline & CDE & 24.73 & 34.23 & 17.91 & 35.63 & 9.95 & 38.19 \\
\hline & CDE-MTV & 21.97 & 34.75 & 13.56 & 36.84 & 5.93 & 40.43 \\
\hline
\end{tabular}

\begin{tabular}{|c|c|c|c|c|c|c|c|}
\hline \multirow{3}{*}{ Bridge } & JPEG & 157.67 & 26.19 & 120.02 & 27.37 & 75.77 & 29.37 \\
\hline & CDE & 150.09 & 26.4 & 113.16 & 27.63 & 81.22 & 29.07 \\
\hline & CDE-MTV & 145.64 & 26.53 & 98.41 & 28.23 & 62.76 & 30.19 \\
\hline \multirow{3}{*}{ Couple } & JPEG & 49.57 & 31.21 & 34.31 & 32.81 & 19.49 & 35.27 \\
\hline & CDE & 48.15 & 31.34 & 36.94 & 32.49 & 22.44 & 35.06 \\
\hline & CDE-MTV & 45.03 & 31.63 & 29.90 & 33.4 & 14.94 & 36.42 \\
\hline \multirow{3}{*}{ Crowd } & JPEG & 40.51 & 32.09 & 27.25 & 33.81 & 14.77 & 36.47 \\
\hline & CDE & 43.95 & 31.74 & 27.59 & 33.75 & 14.98 & 36.41 \\
\hline & CDE-MTV & 39.18 & 32.23 & 25.44 & 34.11 & 11.89 & 37.41 \\
\hline \multirow{3}{*}{ Baboon } & JPEG & 404.18 & 22.1 & 330.00 & 22.98 & 223.28 & 24.68 \\
\hline & CDE & 372.19 & 22.46 & 314.8 & 13.19 & 191.35 & 25.35 \\
\hline & CDE-MTV & 353.71 & 22.68 & 254.93 & 24.10 & 161.78 & 26.08 \\
\hline \multirow{3}{*}{ Pattern } & JPEG & 58.63 & 30.48 & 48.10 & 31.34 & 35.91 & 32.61 \\
\hline & CDE & 45.05 & 31.63 & 53.64 & 30.86 & 29.07 & 33.53 \\
\hline & CDE-MTV & 41.56 & 31.98 & 42.89 & 31.84 & 25.50 & 34.10 \\
\hline \multirow{3}{*}{ Montage } & JPEG & 25.20 & 34.15 & 13.55 & 36.85 & 5.51 & 40.76 \\
\hline & CDE & 23.50 & 34.45 & 17.14 & 35.82 & 9.49 & 38.39 \\
\hline & CDE-MTV & 20.21 & 35.11 & 11.18 & 37.68 & 4.29 & 41.84 \\
\hline
\end{tabular}

Table.5. Summary of Average Unfitness value for various bits/pixel

\begin{tabular}{|c|c|c|c|c|c|c|c|c|}
\hline \multirow{3}{*}{ bpp } & \multicolumn{4}{|c|}{ CDE } & \multicolumn{4}{|c|}{$\begin{array}{l}\text { CDE with Multiple Trial } \\
\text { Vectors }\end{array}$} \\
\hline & \multicolumn{4}{|c|}{ Computation time in seconds } & \multicolumn{4}{|c|}{ Computation time in seconds } \\
\hline & $\begin{array}{l}\text { After } \\
1000\end{array}$ & $\begin{array}{l}\text { After } \\
2000\end{array}$ & $\begin{array}{l}\text { After } \\
\mathbf{3 0 0 0}\end{array}$ & $\begin{array}{l}\text { After } \\
4000\end{array}$ & $\begin{array}{l}\text { After } \\
1000\end{array}$ & $\begin{array}{l}\text { After } \\
2000\end{array}$ & $\begin{array}{l}\text { After } \\
\mathbf{3 0 0 0}\end{array}$ & $\begin{array}{l}\text { After } \\
4000\end{array}$ \\
\hline 0.75 & 116.9 & 97.68 & 90.88 & 88 & 99. & 8 & 7 & 76.90 \\
\hline 1 & 95.71 & 78.31 & 71.45 & 68.8 & 86.9 & 72.44 & 66 & 63.31 \\
\hline 1.5 & 68.53 & 50.74 & 44.16 & 41.8 & 53.3 & 40.81 & 37.06 & 35.40 \\
\hline Avg & 93.75 & 75.58 & 68.84 & 66.30 & 79.81 & 66.31 & 61.15 & 58.54 \\
\hline
\end{tabular}

Table.6. Summary of Average best-of-Generations for various bits/pixel

\begin{tabular}{|c|c|c|c|c|c|c|c|c|}
\hline \multirow{3}{*}{ bpp } & \multicolumn{4}{|c|}{ CDE } & \multicolumn{4}{|c|}{$\begin{array}{l}\text { CDE with Multiple Trial } \\
\text { Vectors }\end{array}$} \\
\hline & \multicolumn{4}{|c|}{$\begin{array}{l}\text { Computation time in } \\
\text { seconds }\end{array}$} & \multicolumn{4}{|c|}{ Computation time in seconds } \\
\hline & $\begin{array}{c}1 \text { to } \\
1000\end{array}$ & $\begin{array}{c}1001 \text { to } \\
2000\end{array}$ & \begin{tabular}{|c|}
2001 \\
to \\
3000
\end{tabular} & $\begin{array}{c}3001 \\
\text { to } \\
4000\end{array}$ & $\begin{array}{l}1 \text { to } \\
1000\end{array}$ & $\begin{array}{c}1001 \text { to } \\
2000\end{array}$ & $\begin{array}{c}2001 \\
\text { to } \\
3000\end{array}$ & $\begin{array}{c}3001 \\
\text { to } \\
4000\end{array}$ \\
\hline 0.75 & 139.66 & 105.19 & 93.70 & 89.31 & 119.54 & 91.25 & 82.28 & 78.21 \\
\hline 1 & 118.50 & 85.22 & 74.25 & 69.98 & 109.27 & 77.60 & 68.85 & 64.67 \\
\hline 1.5 & 100.02 & 57.88 & 46.74 & 42.77 & 87.01 & 45.66 & 38.60 & 36.07 \\
\hline Avg & 119.39 & 82.76 & 71.57 & 67.36 & 105.27 & 71.50 & 63.24 & 59.65 \\
\hline
\end{tabular}


Table.7. Summary of Optimization Accuracy for various bits/pixel

\begin{tabular}{|c|c|c|c|c|c|c|c|c|}
\hline \multirow{4}{*}{ bpp } & \multicolumn{4}{|c|}{ CDE } & \multicolumn{3}{c|}{$\begin{array}{c}\text { CDE with Multiple Trial } \\
\text { Vectors }\end{array}$} \\
\cline { 2 - 10 } & \multicolumn{3}{|c|}{$\begin{array}{c}\text { Computation time in } \\
\text { seconds }\end{array}$} & \multicolumn{3}{c|}{ Computation time in seconds } \\
\cline { 2 - 9 } & $\begin{array}{c}\text { After } \\
\mathbf{1 0 0 0}\end{array}$ & $\begin{array}{c}\text { After } \\
\mathbf{2 0 0 0}\end{array}$ & $\begin{array}{c}\text { After } \\
\mathbf{3 0 0 0}\end{array}$ & $\begin{array}{c}\text { After } \\
\mathbf{4 0 0 0}\end{array}$ & $\begin{array}{c}\text { After } \\
\mathbf{1 0 0 0}\end{array}$ & $\begin{array}{c}\text { After } \\
\mathbf{2 0 0 0}\end{array}$ & $\begin{array}{c}\text { After } \\
\mathbf{3 0 0 0}\end{array}$ & $\begin{array}{c}\text { After } \\
\mathbf{4 0 0 0}\end{array}$ \\
\hline 0.75 & 0.61 & 0.79 & 0.86 & 0.88 & 0.80 & 0.92 & 0.97 & 1.00 \\
\hline 1 & 0.68 & 0.85 & 0.92 & 0.94 & 0.78 & 0.91 & 0.97 & 1.00 \\
\hline 1.5 & 0.76 & 0.89 & 0.94 & 0.95 & 0.87 & 0.96 & 0.99 & 1.00 \\
\hline Avg & $\mathbf{0 . 6 8}$ & $\mathbf{0 . 8 4}$ & $\mathbf{0 . 9 0}$ & $\mathbf{0 . 9 3}$ & $\mathbf{0 . 8 2}$ & $\mathbf{0 . 9 3}$ & $\mathbf{0 . 9 8}$ & $\mathbf{1 . 0 0}$ \\
\hline
\end{tabular}

The Table. 8 shows the $P$ measure of both the algorithms for different target bits/pixel. The $P$ measure value of CDE shows that it does not able to reach the optimal solution at all runs for all images within the preset maximum computation time, whereas CDE with multiple trial vectors is able to reach the optimal solution at all runs for all images. The Table. 9 and Table. 10 shows the AFES measure and SP measure of both the algorithms for different target bits/pixel. Both the measures prefer the lower values. From the Table.9 and Table.10, it is clear that CDE with multiple trial vectors is able to reach the optimal solution consistently within a lesser computation time. AFES and SP measures could not be calculated for CDE for some images because they do not produce any optimal solution over the preset maximum computation time.

Table.8. Probability of Convergence for various bits/pixel

\begin{tabular}{|c|c|c|c|c|c|c|}
\hline \multirow{2}{*}{ Algorithm } & \multicolumn{4}{|c|}{ CDE } & \multicolumn{3}{c|}{$\begin{array}{c}\text { CDE with } \\
\text { Multiple Trial } \\
\text { Vectors }\end{array}$} \\
\hline bpp & $\mathbf{0 . 7 5}$ & $\mathbf{1}$ & $\mathbf{1 . 5}$ & $\mathbf{0 . 7 5}$ & $\mathbf{1}$ & $\mathbf{1 . 5}$ \\
\hline Lena & 1 & 0 & 0 & 1 & 1 & 1 \\
\hline Camera man & 1 & 1 & 0.8 & 1 & 1 & 1 \\
\hline Barbara & 1 & 1 & 1 & 1 & 1 & 1 \\
\hline Clock & 0.2 & 0 & 0 & 1 & 1 & 1 \\
\hline Bridge & 1 & 0.8 & 0 & 1 & 1 & 1 \\
\hline Couple & 0.8 & 0 & 0 & 1 & 1 & 1 \\
\hline Crowd & 0 & 0 & 0.2 & 1 & 1 & 1 \\
\hline Baboon & 1 & 1 & 1 & 1 & 1 & 1 \\
\hline Pattern & 1 & 0 & 1 & 1 & 1 & 1 \\
\hline Montage & 1 & 0 & 0 & 1 & 1 & 1 \\
\hline
\end{tabular}

Table.9. Average Number of Function Evaluations for various bits/pixel

\begin{tabular}{|c|c|c|c|c|c|c|}
\hline \multirow{2}{*}{ Algorithm } & \multicolumn{3}{|c|}{ CDE } & \multicolumn{3}{c|}{$\begin{array}{c}\text { CDE with } \\
\text { Multiple Trial } \\
\text { Vectors }\end{array}$} \\
\hline bpp & $\mathbf{0 . 7 5}$ & $\mathbf{1}$ & $\mathbf{1 . 5}$ & $\mathbf{0 . 7 5}$ & $\mathbf{1}$ & $\mathbf{1 . 5}$ \\
\hline Lena & 74 & - & - & 62 & 90 & 98 \\
\hline Camera man & 73 & 94 & 122 & 32 & 84 & 66 \\
\hline
\end{tabular}

\begin{tabular}{|c|c|c|c|c|c|c|}
\hline Barbara & 58 & 66 & 112 & 50 & 54 & 72 \\
\hline Clock & 123 & - & - & 58 & 80 & 132 \\
\hline Bridge & 72 & 85 & - & 66 & 68 & 76 \\
\hline Couple & 105 & - & - & 34 & 96 & 98 \\
\hline Crowd & - & - & 129 & 72 & 132 & 112 \\
\hline Baboon & 86 & 61 & 62 & 66 & 54 & 46 \\
\hline Pattern & 45 & - & 60 & 36 & 108 & 56 \\
\hline Montage & 103 & - & - & 36 & 106 & 108 \\
\hline
\end{tabular}

The above analysis confirms that $\mathrm{CDE}$ with multiple trial vectors performs better than $\mathrm{CDE}$; however, it is necessary to confirm the results statistically. Hence, one tailed t-test (hypothesis testing) is used to compare the performance of both the algorithms. As a null hypothesis, $\mathrm{H}_{0}$ is assumed that there is no significant difference between the $\mathrm{CDE}$ and $\mathrm{CDE}$ with multiple trial vectors, whereas the alternative hypothesis $\mathrm{H}_{1}$ is that $\mathrm{CDE}$ with multiple trial vectors is more efficient than $\mathrm{CDE}$ at the $5 \%$ significance level.

Table.10. Successful Performance for various bits/pixel

\begin{tabular}{|c|c|c|c|c|c|c|}
\hline \multirow{2}{*}{ Algorithm } & \multicolumn{3}{|c|}{ CDE } & \multicolumn{3}{c|}{$\begin{array}{c}\text { CDE with Multiple Trial } \\
\text { Vectors }\end{array}$} \\
\hline Bpp & $\mathbf{0 . 7 5}$ & $\mathbf{1}$ & $\mathbf{1 . 5}$ & $\mathbf{0 . 7 5}$ & $\mathbf{1}$ & $\mathbf{1 . 5}$ \\
\hline Lena & 74 & - & - & 62 & 90 & 98 \\
\hline Camera man & 73 & 94 & 152.5 & 32 & 84 & 66 \\
\hline Barbara & 58 & 66 & 112 & 50 & 54 & 72 \\
\hline Clock & 615 & - & - & 58 & 80 & 132 \\
\hline Bridge & 72 & 106.25 & - & 66 & 68 & 76 \\
\hline Couple & 131.25 & - & - & 34 & 96 & 98 \\
\hline Crowd & - & - & 645 & 72 & 132 & 112 \\
\hline Baboon & 86 & 61 & 62 & 66 & 54 & 46 \\
\hline Pattern & 45 & - & 60 & 36 & 108 & 56 \\
\hline Montage & 103 & - & - & 36 & 106 & 108 \\
\hline
\end{tabular}

Table.11. One tailed t-test results for different performance Measures

\begin{tabular}{|c|c|c|c|c|c|}
\hline \multirow[b]{2}{*}{ Measures } & \multicolumn{4}{|c|}{$P$ value in $t$ test } & \multirow[b]{2}{*}{$\begin{array}{c}\text { Significance } \\
\text { Level }\end{array}$} \\
\hline & $\begin{array}{c}\text { After } \\
1000 \\
\text { sec }\end{array}$ & $\begin{array}{c}\text { After } \\
2000 \\
\text { sec }\end{array}$ & $\begin{array}{c}\text { After } \\
3000 \\
\text { sec }\end{array}$ & $\begin{array}{c}\text { After } \\
4000 \\
\text { sec }\end{array}$ & \\
\hline $\begin{array}{c}\text { Average Best } \\
\text { Unfitness Value }\end{array}$ & 0.018 & 0.017 & 0.023 & 0.024 & \multirow{3}{*}{0.05} \\
\hline $\begin{array}{c}\text { Average Best of } \\
\text { Generations }\end{array}$ & 0.023 & 0.013 & 0.020 & 0.023 & \\
\hline $\begin{array}{c}\text { Optimization } \\
\text { Accuracy }\end{array}$ & 0.021 & 0.029 & 0.036 & 0.036 & \\
\hline
\end{tabular}

The statistical test is performed only for Average Best Unfitness value, Average Best of Generations, Optimization Accuracy, because for other measures CDE could not able to reach the vicinity of optimal solutions. One tailed t-test is performed on above said measures with 0.05 as the level of 
significance $(\alpha)$ and their $\mathrm{p}$-values are shown in Table.11. The null hypothesis is rejected, when the obtained p-value is less than $\alpha$, otherwise it is not rejected. From the Table.11, it is observed that p-value of all performance measures is less than 0.05 which indicates the rejection of the null hypothesis $\mathrm{H}_{0}$. Therefore, the statistical results confirm that $\mathrm{CDE}$ with multiple trial vectors is more efficient than CDE with a confidence level of $95 \%$.

\section{CONCLUSIONS}

In this paper, a Classical Differential Evolution with multiple trial vectors has been proposed to search the optimal quantization table for the JPEG baseline algorithm. CDE with multiple trial vectors based quantization tables reduces the MSE on an average by $15.6 \%$ and $23.14 \%$ over the CDE based quantization tables and default JPEG quantization tables respectively. Employing multiple trial vectors in a single iteration accelerate the search which in turn improves the convergence speed. Also an extensive comparative analysis has been made between CDE and CDE with multiple trial vectors in terms of their optimization process, accuracy, convergence speed and reliability. The analysis report shows that CDE with multiple trial vectors guarantees an optimal solution in a lesser time. Also the empirical results have been confirmed by statistical hypothesis test (t-test). Possible direction for the future work includes the employing of different multiple trial vector generation strategies for this application by considering the time taken for computation.

\section{REFERENCES}

[1] W3Tech, "Usage of JPEG for websites", Available at:www.w3techs.com/technologies/details/im-jpeg/all/all. Accessed on 2017.

[2] Gregory K. Wallace, "The JPEG still Picture Compression Standard", Communications of the ACM-Special Issue on Digital Multimedia Systems, Vol. 34, No. 4, pp.30-44, 1991.

[3] S. Viswajaa, B. Vinoth Kumar and G.R. Karpagam, "A Survey on Nature Inspired Meta-Heuristics Algorithms in Optimizing the Quantization Table for the JPEG Baseline Algorithm", International Advanced Research Journal in Science, Engineering and Technology, Vol. 2, No. 4.pp. 114-123, 2015.

[4] S.P. Naresh, B. Vinoth Kumar and G.R. Karpagam, "A Literature Review on Quantization Table Design for the JPEG Baseline Algorithm", International Journal of Engineering and Computer Science, Vol. 4, No. 10, pp. 14686-14691, 2015.

[5] B.G. Sherlock, A. Nagpal and D.M. Monro, "A Model for JPEG Quantization", Proceedings of International Symposium on Speech, Image Processing and Neural Networks, pp. 176-179, 1994.

[6] Yung-Gi Wu, "GA-based DCT Quantization Table Design Procedure for Medical Images", IEE Proceedings-Vision, Image and Signal Processing, Vol. 151, No. 5, pp. 353-359, 2004.

[7] M.R. Boyandi, E. Dehghani and M.E. Moghaddam, "A NonUniform Image Compression using Genetic Algorithm", Proceedings of $15^{\text {th }}$ International Conference on Systems, Signals and Image Processing, pp. 315-318, 2008.
[8] Shuwang Chen, Tao An and Litao Hao, "Discrete Cosine Transform Image Compression Based on Genetic Algorithm", International Conference on Information Engineering and Computer Science, pp. 1-3, 2009.

[9] Beatrice Lazzerini, Francesco Marcelloni and Massimo Vecchio, "A Multi-Objective Evolutionary Approach to Image Quality/Compression Trade-Off in JPEG Baseline Algorithm", Applied Soft Computing, Vol. 10, No. 1, pp. 548-561, 2010.

[10] B. Vinoth Kumar, G.R. Karpagam and N. Vijaya Rekha, "Performance Analysis of Deterministic Centroid Initialization Method for Partitional Algorithms in Image Block Clustering", Indian Journal of Science and Technology, Vol. 8, No. 7, pp. 63-73, 2015.

[11] B Vinoth Kumar and Karpagam Manavalan, "Knowledge based Genetic Algorithm Approach to Quantization Table Generation for the JPEG Baseline Algorithm", Turkish Journal of Electrical Engineering and Computer Sciences, Vol. 24. No. 3, pp. 1615-1635, 2016.

[12] B Vinoth Kumar and Karpagam Manavalan, "A Problem Approximation Surrogate Model (PASM) for Fitness Approximation in Optimizing the Quantization Table for the JPEG Baseline Algorithm", Turkish Journal of Electrical Engineering and Computer Sciences, Vol. 24, No. 6, pp. 4623-4636, 2016.

[13] S.M. Guo, J.S.H Tsai, W.H. Chang, B.H. Wu and S.J. Guo, "Chaos Evolutionary Programming based JPEG Quantization Table Generation Scheme", Proceedings of $5^{\text {th }}$ International Conference on Informatics and Systems, pp. 1-7, 2007.

[14] Huizhu Ma and Qiuju Zhang, "Research on Cultural-based Multi-Objective Particle Swarm Optimization in Image Compression Quality Assessment", Optik-International Journal for Light and Electron Optics, Vol. 124, No. 10, pp. 957-961, 2012.

[15] Milan Tuba and Nebojsa Bacanin, "JPEG Quantization Tables Selection by the Firefly Algorithm", Proceedings of International Conference on Multimedia Computing and Systems, pp. 1-6, 2014.

[16] B. Vinoth Kumar and M. Karpagam, "Differential Evolution versus Genetic Algorithm in Optimising the Quantisation Table for JPEG Baseline Algorithm", International Journal of Advanced Intelligence Paradigms, Vol. 7, No. 2, pp. 111135, 2015.

[17] B. Vinoth Kumar and Karpagam Manavalan, "Knowledge based Differential Evolution Approach to Quantization Table Generation for the JPEG Baseline Algorithm", International Journal of Advanced Intelligence Paradigms, Vol. 8, No. 1, pp. 20-41, 2016.

[18] B. Vinoth Kumar, G.R. Karpagam and S.P. Naresh, "Generation of JPEG Quantization Table using Real Coded Quantum Genetic Algorithm", Proceedings of IEEE International Conference on Communication and Signal Processing, pp. 1705-1709, 2016.

[19] Rainer Storn and Kenneth Price, "Differential Evolution: A Simple and Efficient Adaptive Scheme for Global Optimization over Continuous Spaces", Journal of Global Optimization, Vol. 11, No. 4, pp. 341-359, 1997.

[20] Swagatam Das and Ponnuthurai Nagaratnam Suganthan, "Differential Evolution: A survey of the State-of-the-Art", 
IEEE Transactions on Evolutionary Computation, Vol. 15, No. 1, pp. 4-31, 2011.

[21] Bernabe Dorronsoro and Pascal Bouvry, "Improving Classical and Decentralized Differential Evolution with new Mutation Operator and Population Topologies", IEEE Transactions on Evolutionary Computing, Vol. 15, No. 1, pp. 67-98, 2011.

[22] Ivan Zelinka, Vaclav Snasael and Ajith Abraham, "Handbook of Optimization: From Classical to Modern Approach", Springer, 2012.

[23] Yong Wang, Zixing Cai and Qingfu Zhang, "Differential Evolution with Composite Trial Vector Generation
Strategies and Control Parameters", IEEE Transactions on Evolutionary Computation, Vol. 15, No. 1, pp. 55-66, 2011.

[24] Z. Hui-Fang, H. Wei and W. Jin-Song, "Clustering-Based Differential Evolution with Composite Trial Vector Generation Strategies and Control Parameters", Proceedings of Joint International Conference on Service Science, Management and Engineering. pp. 1-6, 2016.

[25] Kenneth Price, Rainer M. Storn and Jouni A Lampinen, "Differential Evolution: A Practical Approach to Global Optimization", Springer, 2006. 